Brit. J. industr. Med., 1949, 6, 184.

\title{
TALC PNEUMOCONIOSIS
}

\author{
BY \\ A. I. G. McLAUGHLIN \\ H.M. Medical Inspector of Factories \\ ENID ROGERS \\ Member of the Silicosis Medical Board \\ AND \\ K. C. DUNHAM \\ Chief Petrographer, H.M. Geological Survey and Museum
}

(RECEIVED FOR PUBLICATION, DECEMBER 20, 1948)

In September, 1946, we had the opportunity of examining the lungs of a man who had died from rheumatic endocarditis and pneumoconiosis and who for most of his industrial life had been exposed to talc dust.

\section{Case History}

He was 51 years of age and had worked since he left school at 14 years of age in a rubber tyre factory for thirty-seven years. The only break in this employment was a period of four years' service in the 1914-18 war, mostly spent in India. In the factory he had worked on a tyre-extruding machine. While a tyre is being extruded, powdered talc (or French chalk) is gently blown through it by means of compressed air to prevent the rubber surfaces from sticking together. The tyre is cut into suitable lengths and the outer surfaces are patted with talc powder. Exhaust ventilation devices are installed to prevent gross contamination of the air with dust, but it is likely that over a period of years there had been considerable exposure to talc dust arising mainly from the open end of the tyre and during the patting operation.

Inquiry into the man's family history showed that his father had died from "blood pressure" and his mother from dropsy; his two brothers had both recently died, one from a gastric ulcer and the other from a sudden heart attack. He himself had suffered from chorea at the age of 12 years, the attack lasting for seven months. Since then he had no further illness and had led a strenuous athletic life until 1939, when he began to suffer from a persistent pain in the right hypochondrium. His alimentary tract was radiographed at hospital, but nothing was found to account for the pain. In December, 1944, he was admitted to hospital for observation because he still complained of the pain. In hospital it was noticed that he was short of breath while lying in bed. A radiograph of the chest was taken and it was reported that he had an "industrial chest" or " fibrous lung." On return to work after 10 weeks' absence he was given a job as a gatekeeper.

On clinical examination by one of us (A.I.G.McL.) in August, 1945, the man was found to be fairly well nourished, slightly dyspnœeic at rest, but with no obvious cyanosis of the extremities, face, or ears; there was no clubbing of the fingers and no cedema of the-legs. The chest measured 34 inches with an excursion of two inches between deep inspiration and forced expiration, that is to say, the chest movement was diminished. The breath sounds were distant over the whole of the lung fields (a common finding in the pneumoconioses), but no other abnormal signs were found. Signs of well-marked aortic incompetence with hypertrophy of the left ventricle were also present. The pulse rate was 80 per minute, and the blood pressure $170 / 50 \mathrm{~mm}$. Hg. When the abdomen was examined there was slight tenderness over the right hypochondrium, but the liver was normal in size and ascites was not present. Other systems were normal.

$\boldsymbol{X}$-ray Examination.-By the courtesy of Dr. J. S. Harper, County Tuberculosis Officer for Wiltshire, we were able to see a series of $x$-ray films of the chest taken at intervals of six months from February, 1945, until August, 1946. Three of them are reproduced here (figs. 1, 2, and 3). They all show the enlargement of the heart shadow, and small closely packed nodular shadows in both lung fields. Those on the right side are clearly defined, whereas those on the left are "fluffy" and indistinct. The line of the right diaphragm is clear, whereas that of the left is blurred. The last film (fig. 3) taken shortly before his death shows much increased basal mottling, which, taking into account the short interval since the previous film, may be interpreted as shadows of lung congestion from a failing heart.

Dr. Harper, who had kept the patient under observdtion for some years, did not find bacteriological or clinical evidence of pulmonary tuberculosis. The man died in August, 1946, and a post-mortem examination was made by Dr. E. M. Darmady of Salisbury. He sent us the lungs for more detailed examination. The causes of death were (1) congestive heart failure due to longstanding rheumatic endocarditis, and (2).pneumoconiosis.

Pathology.-The lungs had been fixed in formalin before they were received. The root glands were moderately enlarged but not fibrotic. Except for adhesions over the right base, the pleuræ were normal. The whole of the left lung and the lower lobe of the right were moderately congested. Throughout the lung substance were scattered small grey nodules, more numerous in the lower lobes. In the right lower lobe and in the upper pole of the left lower lobe the nodules had coalesced to form small masses. These confluent lesions bore some superficial resemblance to infective silicosis 
but no naked-eye evidence of tuberculosis was present in either lung. A moderate degree of emphysema was apparent in those parts of the lungs free from congestion. The isolated nodules were small, rarely exceeding 2 or $3 \mathrm{~mm}$. in diameter, poorly defined, and only just palpable. They felt tough rather than hard, and lacked the compact pattern of classical silicotic nodules.

On microscopic examination the nodules were seen to consist of loosely woven fibrous tissue. The larger nodules were made up of the coalescence of a number of smaller ones, the fibres appearing to be arranged concentrically round small vessels, giving the impression of whorling but not quite in the pattern characteristic of silicosis. Many of these vessels had fibrous thickened intima. Some nodules were in close relationship with a respiratory bronchiole and in this respect resembled the lesions of asbestosis, silicosis, and coal-miners' pneumoconiosis, but no focal emphysema was seen (iigs. 4 and 5). Some dust particles within phagocytes appeared at the periphery of each nodule; within the nodule itself were many fibre-like structures up to $40 \mu$ in length arranged singly and in clumps. Some " curious bodies," very like asbestosis bodies (figs. 5, 6, and 7) were also seen. Under polarized light all nodules were found to be closely packed with doubly refractile particles, each resembling a short fibre; no flake-like particles ware visible. The nature of the fibres is discussed below.

In all sections studied there were found small numbers of " curious bodies" resembling but not completely identical with asbestosis bodies. They were mostly single, but occasionally in clumps of three and four seen usually at the edge of a confluent lesion. One was found amongst the débris in an alveolus. In scrapings from the cut surface of a nodule they were fairly numerous. They were pale lemon-yellow rods, rather like dumbbells, the end-masses often consisting of rosettes, which could sometimes be found separate from the rods in the lung tissue. They had a somewhat finer central core than asbestosis bodies and did not show such variation in shape. Like asbestosis bodies they gave a positive prussian blue reaction.

The presence of these curious bodies led to a further investigation of the industrial history. Asbestos had never been used in the factory where the man had been employed. On the other hand asbestine, a fibrous variety of talc, had been used from time to time in the factory, but not on the rubber extruding machines. The mineralogy of the dust particles in the lung, described below, show that the majority were in the form of short fibres which could easily have formed the basis of the curious bodies by the deposition of iron salts on them.

Curious bodies closely resembling these and the true asbestosis body have been found by one of us (E.R.)in South African gold miners who had never worked in the asbestos industry (Williams, 1939) while " black-cored" curious bodies are often found in the lungs of coalminers and coal-trimmers (Williams, 1934). The findings in each of these two investigations suggested that they were due to the chance inhalation of a fibrous mineral not necessarily related to asbestos or coal.

Chemical Analysis.-The right lung from the present case was sent to Dr. H. E. Harding of the University of Sheffield for chemical analysis. We are indebted to him for the following report :

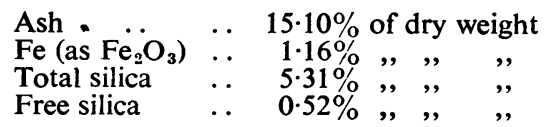

Dr. Harding suggested that owing to technical difficulties the last two figures were probably too high, and he later submitted the ash to $x$-ray analysis. He reported that the ash gave only a very faint quartz line, suggesting that there was less than 1 per cent. of quartz present and therefore probably less than 0.06 per cent. of free silica.

\section{Occurrence of Talc}

Talc is hydrated magnesium silicate $\left(\mathrm{Mg}_{3} \mathrm{Si}_{4} \mathrm{O}_{10}\right.$ $\left.(\mathrm{OH})_{2}\right)$ and in its compact form is known as steatite or soapstone. It is mined in such parts of the world as U.S.A., Canada, France, Italy, Norway, and India, and it occurs in both flaky and fibrous forms. Jones (1943) says that the chief deposits of talc and soapstone occur in altered magnesia-rich calcareous rocks such as dolomite, marble, and magnesian limestone. The purest talc deposits occur in association with dolomite and marble. Talc also occurs in altered basic rocks such as serpentines, and again as thin beds in mica schists. "The largest talc deposit in Europe, on the northern slope of the Pyrénées, occurs as beds in mica schist."' Commercial talcs contain a number of related minerals and impurities. They may include antigorite (hydrated magnesium silicate), magnesite or members of the magnesite-chalybite series of carbonates, dolomite (calcium magnesium carbonate), tremolite (calcium magnesium silicate), and spinels (chromite, magnetite, etc.). Talc rarely occurs in association with free quartz and commercial talcs are normally free from quartz. It may be recalled that asbestos is the commercial name applied to the fibrous amphiboles, including tremolite, actinolite, anthophyllite, and crocidolite. These differ from talc in consisting wholly or largely of acicular crystals, though, as noted below, talc may in certain instances arise as an alteration-product of tremolite ; it may replace anthophyllite also, inheriting in both cases an imperfectly fibrous form.

\section{Mineralogy of the Particles in the Lung}

An investigation of the mineralogy of the contents of the lung, and of the talc used in the factory was carried out in the petrographical laboratories of the Geological Survey. Sections of the lung had, as already noted, revealed numerous birefringent particles (figs. 8, 9, and 10). These proved to be straight or (rarely) slightly curved fibres, showing positive elongation and extinction parallel with the 
plane of polarization of the light. Separation of the mineral from the lung tissue was carried out by Mr. C. O. Harvey by means of the following procedure, adopted to avoid as far as possible any chemical or physical alteration of the inorganic silicate material :

The lung sample was moistened with 40-" vol " $\mathrm{H}_{2} \mathrm{O}_{2}$ and allowed to stand for a few minutes; $10 \% \mathrm{NaOH}$ was then added and complete disintegration of the tissue was effected by boiling; after centrifuging, boiling with $10 \% \mathrm{NaOH}$ was repeated. The residue was then centrifuged, washed with water, centrifuged, and digested with hot $4 \mathrm{~N} \mathrm{HCl}$. After further centrifuging, and washing with water and ethyl alcohol, the sample was shaken with $\mathrm{CHCl}_{3}$, boiled for a few seconds, cooled, centrifuged, and washed with ether.

Microscopical examination of the residue (ENQ 933*) showed that the organic tissue had been completely removed. The residue consisted almost entirely of straight fibres, somewhat curved fibres, and shreds having maximum refractive index 1.589, the Z-direction being parallel with the length of the fibres. The minimum refractive index of the fibres was near or slightly below 1.546 . The fibres ranged up to 10 microns maximum length, but many were 4-5 $\mu$ long. A few plates up to $5 \mu$ diameter, showing low birefringence and refractive index near 1.589 were noted: An exhaustive search for fibres of amphibole showing inclined extinction failed to reveal any such fibres. A few tiny granules of an opaque substance were noted in the powder.

The accepted mineralogical data for talc shows that it is a platy mineral with $Z$. parallel with the basal (001) cleavage, having refractive indices $\mathrm{n} \alpha=1.538-1.545, \mathrm{n} \gamma=1.575-1.590$. The observations on the lung residue are thus consistent with talc except in the acicular habit of the mineral. That the mineral is in fact talc was confirmed by $x$-ray powder photographs of the residue taken by Mr. H. J. Dothie at the Government Laboratory. These are compared with lines shown by a standard sample of talc supplied by Dr. T. A. Lloyd Davies of Boots Chemists Ltd., Nottingham, in fig. 11. Mr. Dothie's measurements of the lines shown by the material from the lung are as follows :

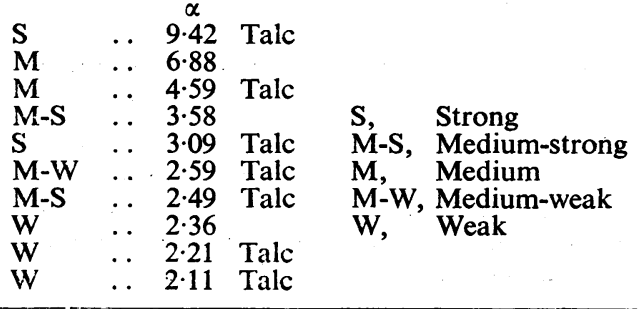

* Numbers in brackets refer to slices in the Geological Survey and Museum collection.

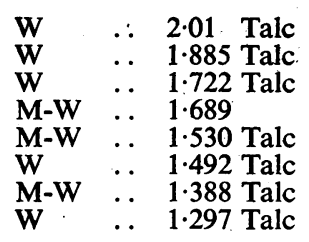

Another extraction of material from the lung, carried out with $\mathrm{H}_{2} \mathrm{O}_{2}$ and $\mathrm{NaOH}$, but without acid treatment, failed to show any particles of carbonate in the mineral residue.

\section{Types of Talc used in the Factory}

Up to 1939 the talc used in the factory came from Norway, so that for thirty years the man's exposure was solely to the dust of Norwegian talc. On the outbreak of war, this could not be obtained and the following substitutes were used : (1) "French chalk substitute," a by-product of china clay mining; (2) Canadian talc and (3) Indian talc, which however was not used on the extruding machines. For the last five years of his working life the man was exposed to the dust of "French chalk substitute" and Canadian talc, but the bulk of his exposure was to the dust of Norwegian talc.

Samples of the Norwegian and Canadian talcs and the "French chalk substitute" "were microscopically examined. The Norwegian material (ENQ 935) consisted predominantly of talc with optical properties similar to those displayed by the mineral from the lung. While it was predominantly platy in form, a significant feature was the presence among the finest-grained material of a high proportion of fibres exactly like those in the lung. The sample also contained a substantial proportion of a carbonate having $\mathrm{n}_{w}$ ranging from $1 \cdot 714-1 \cdot 720$, probably breunnerite (ferriferous magnesite) though these data are also consistent with a medium ankerite. Extraction with hot dilute $\mathrm{HCl}$ gave an approximate figure of 29 per cent. for the carbonate-content of the talc. Very minor quantities of chlorite, tremolite, and titano-magnetite or ilmenite (partly "leucoxenized") were also noted. A mineralogical report on a different sample, supplied by the owners of the factory, was in general agreement with the above, except that the tremolite was stated to be common among the minor constituents.

The Canadian talc (ENQ 936) showed properties closely similar to those of the Norwegian material ; the carbonate-content of the sample amounted to approximately 28 per cent. and the ordinary-ray refractive index of grains ranged from 1.710 to 1.717. The talc again showed a substantial proportion of fibrous material, particularly in sizes less than $20 \mu$. 
Rutile and an opaque spinellid were present in very small amounts.

The "French chalk substitute" (ENQ 934) consisted predominantly of white mica (probably mainly muscovite but possibly including some illite), and kaolinite. Platy forms predominated, but among the smallest material $(1-15 \mu)$ a proportion of fibrelike shreds was noted. A definite though small amount of free quartz was found; other minor constituents include tourmaline, biotite, and an alkali feldspar.

It will be noted that no evidence of minerals diagnostic of the "French chalk substitute" was found in the examination of the lung residue. The talc could, however, equally well have come from either the Norwegian or the Canadian samples.

The mineralogical observations establish clearly that fine grinding of talc gives rise to material having individual fibre form and perhaps - suggest the presence of a previously unsuspected second cleavage parallel with the $Z$-direction. It has been stated by Berkelhamer (1943) that talc may inherit prismatic-acicular (or long-fibre) form by pseudomorphing tremolite. Thus it might be suggested that the fibres in the samples discussed above originated by alteration of an amphibole. That this is not necessarily the case was, however, proved by examination of talc from Corriecharmaig, Perth (S. 36767A), which occurs as an alteration of a serpentine mass containing no amphibole. Fineground talc from this locality shows acicular forms identical with those of the Norwegian and Canadian samples.

\section{Review of Literature}

The mineral talc has many uses in industry as a filler for paper, soaps, and paints, as an inert extender, as a dusting powder, and as an absorbent. In the rubber industry talc or French chalk is used freely to prevent the rubber surfaces from sticking together. While a tyre is being " extruded " finely divided talc powder is blown through the cavity by a low-pressure stream of compressed air and the outer surfaces of the tyre are also dusted with the powder. Workers in rubber factories are exposed during the course of their working lives to the inhalation of a good deal of talc dust. Talc pneumoconiosis has been described from time to time, but the number of cases is small enough to suggest that the capacity of the dust to produce fibrosis is low.

In this country Merewether (1933-4) examined 11 rubber tyre workers who had been exposed to the inhalation of talc dust for periods ranging from ten to thirty-two years. He found that the radiographic appearances suggested the presence of a diffuse interstitial fibrosis of the lungs, but that on clinical examination little or no evidence of disability was present. Even after thirty years' exposure only a peribronchial increase of fibrous tissue had resulted. He suggested that the radiographic appearances seen really reflected the actual dust in the lungs, together with any associated congestion, rather than the presence of a diffuse fibrosis. In 1934 he examined thirteen additional workers with exposures ranging from four and a half months to forty years, and the results of examination supported his previous conclusion. The dust of French chalk has in fact been shown to be radio-opaque (McLaughlin and others, 1945).

A few years earlier Zanelli (1931) in Italy described the case of a woman of 27 who had worked for five years in the tyre department of a rubber factory where she had been exposed to clouds of dust. She had complained of gastric symptoms and loss of the sense of smell, and she had hyperæmia of the conjunctiva. $X$-ray films of the chest showed an early tuberculous infiltration in the right subclavicular region, enlarged hilar shadows, diminished transparency of the right lung as compared with the left, and accentuation of the "lymphatic reticulation" of the lung. Later films showed the development of nodulation. No histological studies were made, and the presence of pulmonary tuberculosis also detracts from the value of the case as one of proved pneumoconiosis due to talc dust. The first case to be reported as talc pneumoconiosis also had tuberculosis. This was in 1896 when Thoral of Nuremberg described the pathological features of the lungs of a woman of 44 who had been exposed for several years to the dust of steatite. The lungs were greenish brown, the lower lobes being deeply stained. Masses of pigment composed of steatite dust was found in the alveolar walls and in connective tissue septa, but " there was no formation of agglomerations." Another case was studied by Sand of Belgium in 1910 and mentioned by Carozzi and others. This was a woman who had worked for several years in an atmosphere of talc dust during her exposure. Histologically the lungs showed many talc particles in the alveoli and in the connective tissue, but " without great reaction." Another unpublished case referred to by various authors was that of Cunningham of Toronto. He examined clinically and radiographically a man who had worked for nine years in talc dust and found evidence of pneumoconiosis.

It will be seen that these early reports of talc pneumoconiosis are somewhat inconclusive, but since 1933 investigators in the U.S.A. have devoted a good deal of attention to the subject. Dreesen (1933) examined a number of workers exposed to silicate dusts including fifty-seven in a tremolite talc 
mine and mill. Those employed longer than five years showed first-stage pneumoconiosis, the $x$-ray appearances being of a fine bilateral fibrosis. These changes were not accompanied by disability. Dreesen and Dalla Valle (1935) carried out a further survey of two talc-mining and manufacturing plants in Georgia. Clinical and $x$-ray examinations showed that sixteen mill-workers out of thirty-three exposed to high concentrations of dust, and six out of thirteen miners, had pneumoconiosis. In a group exposed to low concentrations of dust no pneumoconiosis was found ; five patients with pneumoconiosis also had tuberculosis. It was concluded that Georgian talc was more injurious than tremolite talc.

Nuck and Szcepanski (1939) reviewed the literature of talc fibrosis and added some cases of their own. In a mineralogical study of silicosis, Emmons and Wilcox (1937) demonstrated that both talc and amphibole asbestos may yield on prolonged treatment in blood serum as much soluble silica as does quartz or amorphous silica (opal). Riddell (1940) reported the results of examination of thirtyseven workers engaged in grinding Canadian talc for five to eighteen years; thirteen workers had fibrosis resembling silicosis. In one case under observation for some years the lesions had neither receded nor regressed. Gardner (1940) noted that among three hundred films of talc workers fifty showed some evidence of pulmonary reaction, which in seventeen cases was suggestive of the nodular type. The free silica content of the ore varied from 2 to 20 per cent. In a young man exposed to talc with a rock content of 20 per cent., far advanced discrete nodulation was noted.

Siegal and others (1943) say that " from a survey of the literature it appears that while experimental studies have hitherto been inconclusive, clinical studies have tended to indicate that talc dust is capable of producing injurious pulmonary changes." They report a survey of talc miners and millers in St. Lawrence County, New York, where the talc is of the fibrous variety known as asbestine, and with it is found tremolite; anthophyllite, another fibrous silicate, is also present in these talc deposits. (Jones includes anthophyllite amongst the asbestos group of minerals.) The free silica content is less than 1 per cent. Studies of the dust showed the presence of fine straight needle-like fibres. In a group of 221 tremolite talc miners and millers advanced fibrosis was found in thirty-two men ( 14.5 per cent.). All cases of fibrosis occurred in men with ten years' and more exposure. The fibrosis was a fine diffuse type with radiographic appearance of granulation or nodulation in a hazy background. It tended to be disabling in character and was often accompanied by dyspnœa, cough, and fatigue. There was some evidence of an increased susceptibility to tuberculosis. An interesting finding was the presence of " talc plaques" in the periphery of the lungs in 6.3 per cent. of all workers examined. These plaques occur in the absence of other abnormal $x$-ray shadows and are not accompanied by signs or symptoms. They conclude that tremolite dust is, like asbestos, capable of causing a disabling pneumoconiosis. It might be interpolated here that Gloyne (1938), in describing the pathology of asbestosis, drew attention to the presence of "stiff, yellow, and horn-like plaques" in the parietal pleura. Porro and others (1942) described fifteen cases of pneumoconiosis among talc miners exposed to an average dust concentration of 52 million particles per cubic foot : five of these cases came to autopsy, and all showed a diffuse fibrosing pneumoconiosis. Asbestosis bodies were found in all five cases, and they suggest that talc pneumoconiosis (in these cases) and asbestosis are the same disease.

Porro and Levine (1946) reported another case of a talc worker of 45 years of age who died from infarction of the lung. Histologically the lungs showed a fibro-cellular reaction with asbestosis bodies.

Reichmann (1944) described twenty-one radiographs of lead plate founders who had been exposed to talc dust. Abnormal shadows began to appear after ten years at work. Pruvost (1946) reported a case of pneumoconiosis in a woman who had been brushing rabbit skins impregnated with talc. The $x$-ray picture resembled pseudo-tumoral form of the silicosis complicated by pneumothorax.

Perry (1947) briefly reviewed the literature of talc pneumoconiosis and illustrated the condition by radiographs of two talc workers : (1) F., aged 48 , exposed for twenty years to talc dust in a rubber tyre factory and who had complained of severe cough and dyspnca ; and (2) F., aged 52, exposed for twenty-five years to talc also in a rubber tyre factory, and who had complained of severe cough, purulent sputum, and dyspnœa. No further details were added, but it should be noted that the $x$-ray appearances resembled those seen in asbestosis, illustrations of which are also reproduced in the same paper.

Inhalation animal experiments with talc dust have so far proved inconclusive and it is not possible to deduce from the results of intraperitoneal injections of dust what will be the effect on the lungs. It might be recalled that on intraperitoneal injection asbestos has been classified as an inert dust. On the other hand there have recently been reported many instances, in this country and America, of granulomatous lesions occurring in the tissues as a result of contamination by talc glove-powder during surgical operations. Roberts (1947), writing in the British 

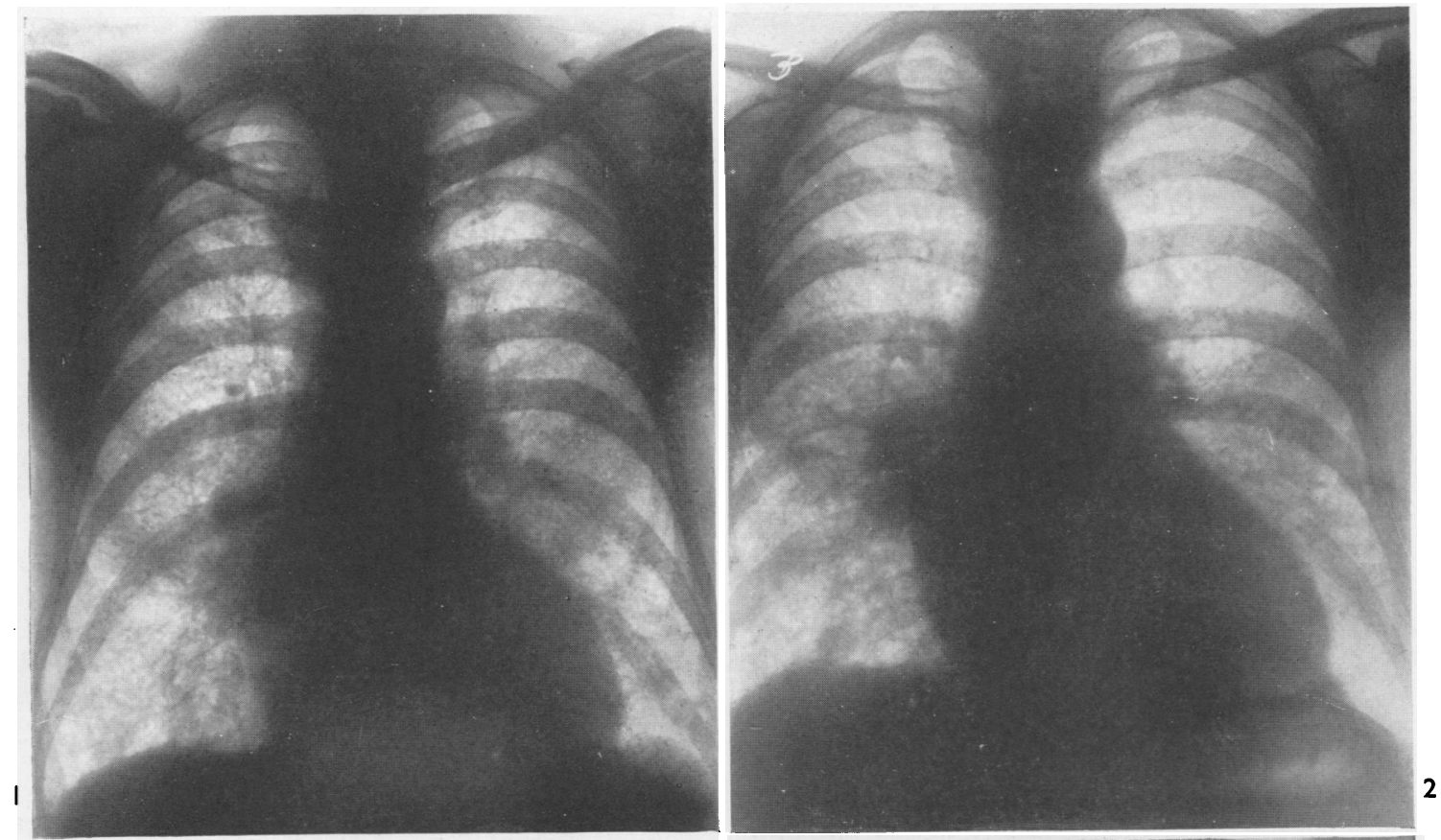

Fig. 1 (top left).-Chest radiograph taken on Jan. 25, 1945 , showing nodular shadows distributed generally over both lung fields. There are wellmarked root shadows and the heart is large. The line of the right diaphragm is clear, but the left is blurred. Talc pneumoconiosis.

Fig. 2 (top right). - The Chest radiograph taken on Nov. 5, 1945, showed little change.

FIG. 3 (lower).-Chest radiograph taken on March 7, 1946, five months before the patient's death. In addition to nodular shadows shown in two earlier films there is much diffuse shadowing over both bases, probably caused by congestion due to a failing heart.

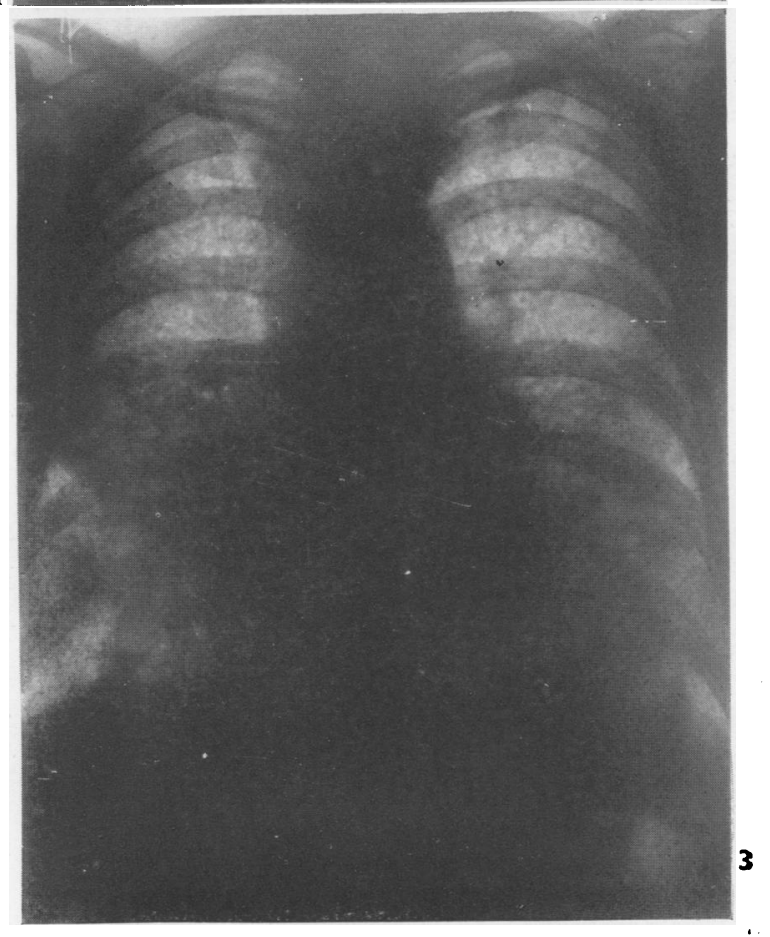




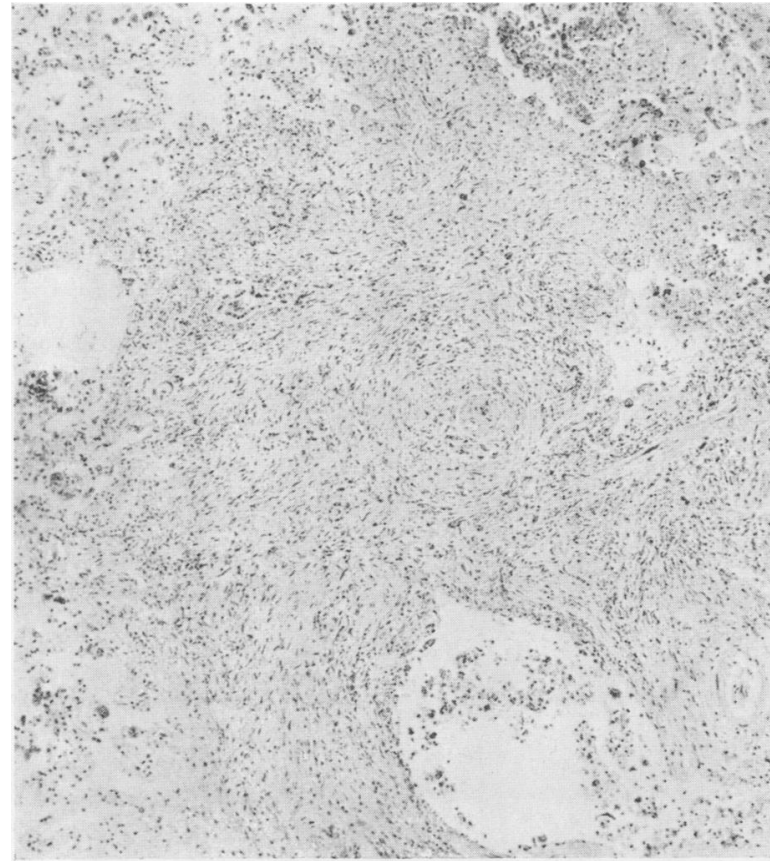

FIG. 4.-Photomicrograph of a fibrotic nodule from the right upper lobe, showing the relation of fibrosis to the respiratory bronchiole, and dust phagocytes at the periphery of the nodule. $\times 65$.

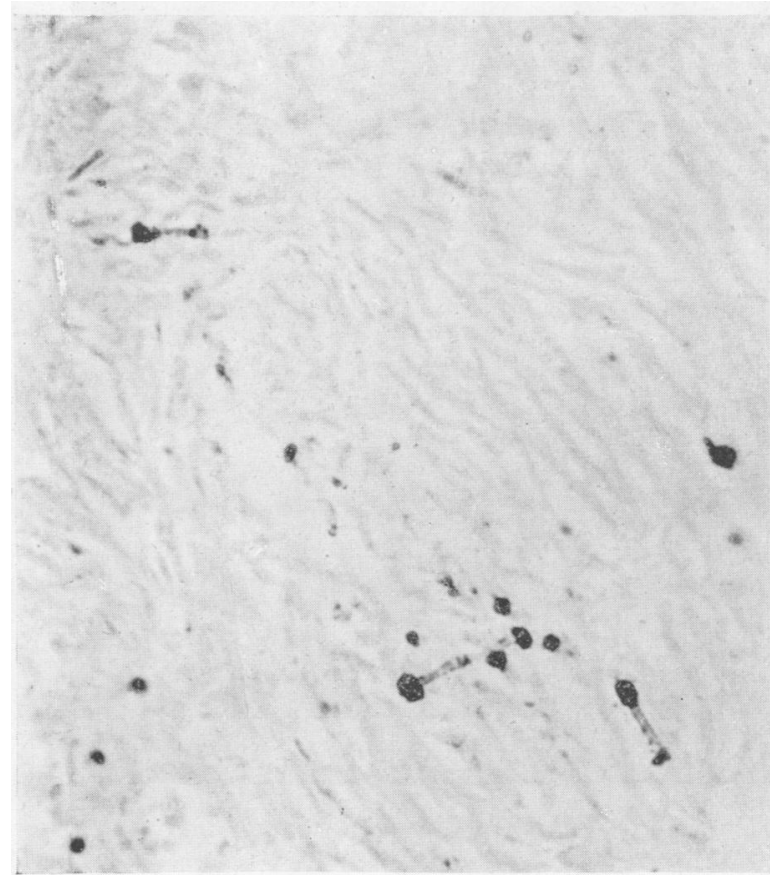

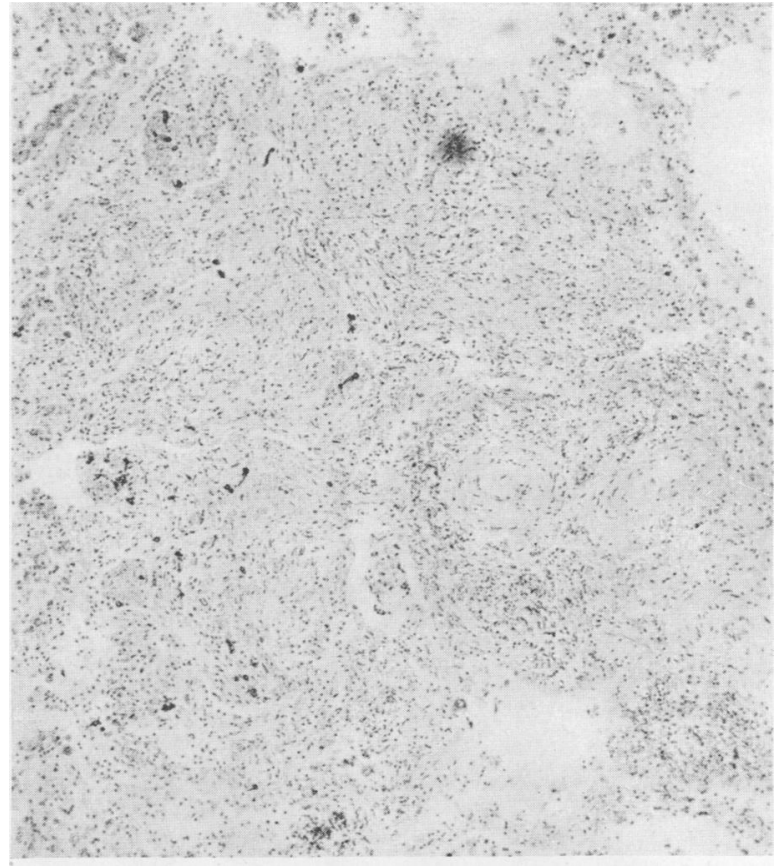

FIG. 5.-Photomicrograph of a nodule from the right apex, showing curious bodies. $\times 65$.

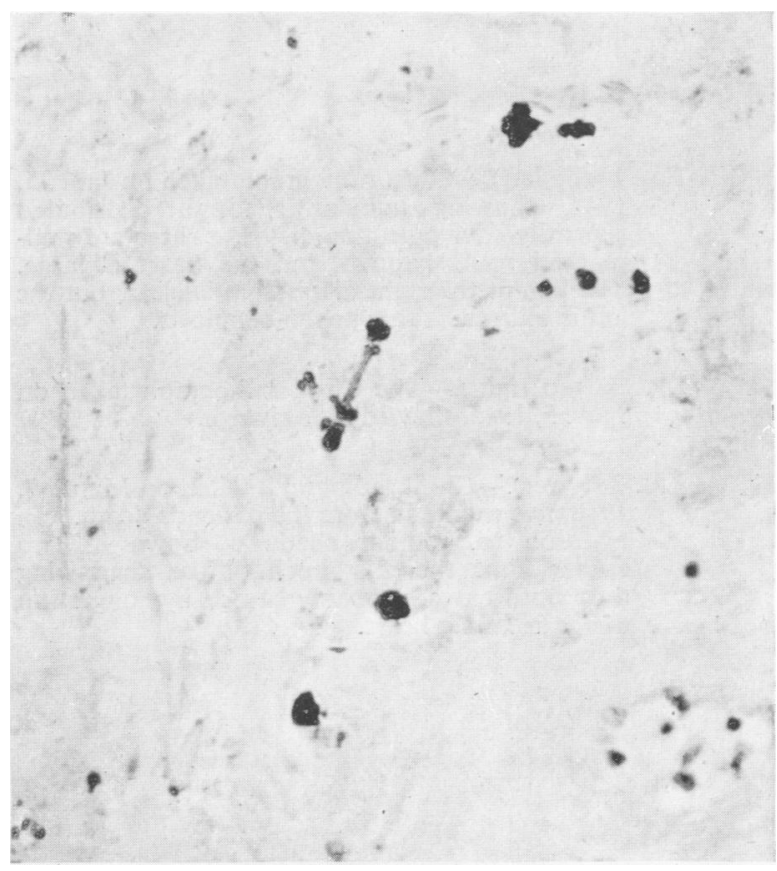

FIGS. 6 and 7.-Photomicrographs showing curious bodies. $\times 350$ 


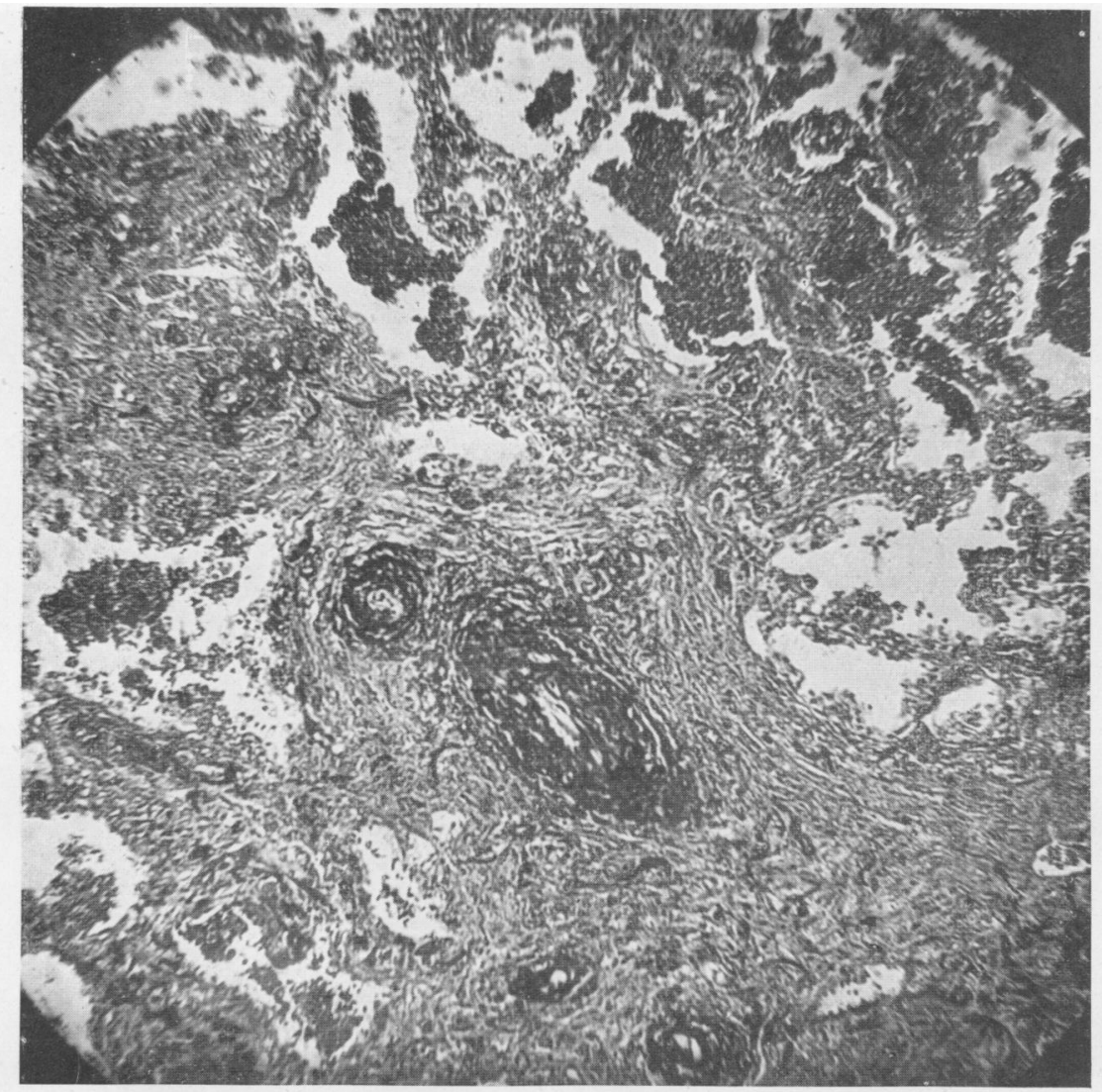

Fig. 8.-Photomicrograph of lung section of worker exposed to talc dust taken on Vickers projection microscope by transmitted light. $\times 127$.

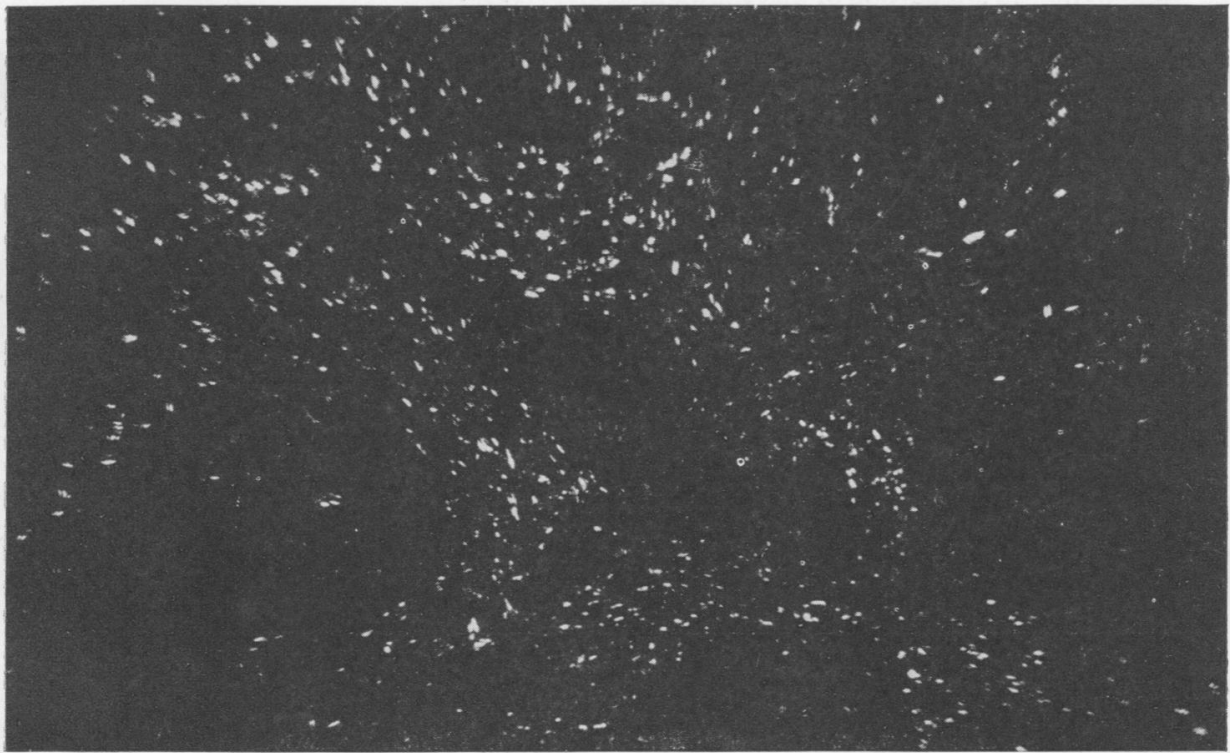

Fig. 9.-Low-power photomicrograph of lung section of the same worker photographed in polarized light on the Vickers projection microscope. The field photographed is a portion of that in fig. 8, and shows birefringent dust particles. $\times 127$. 


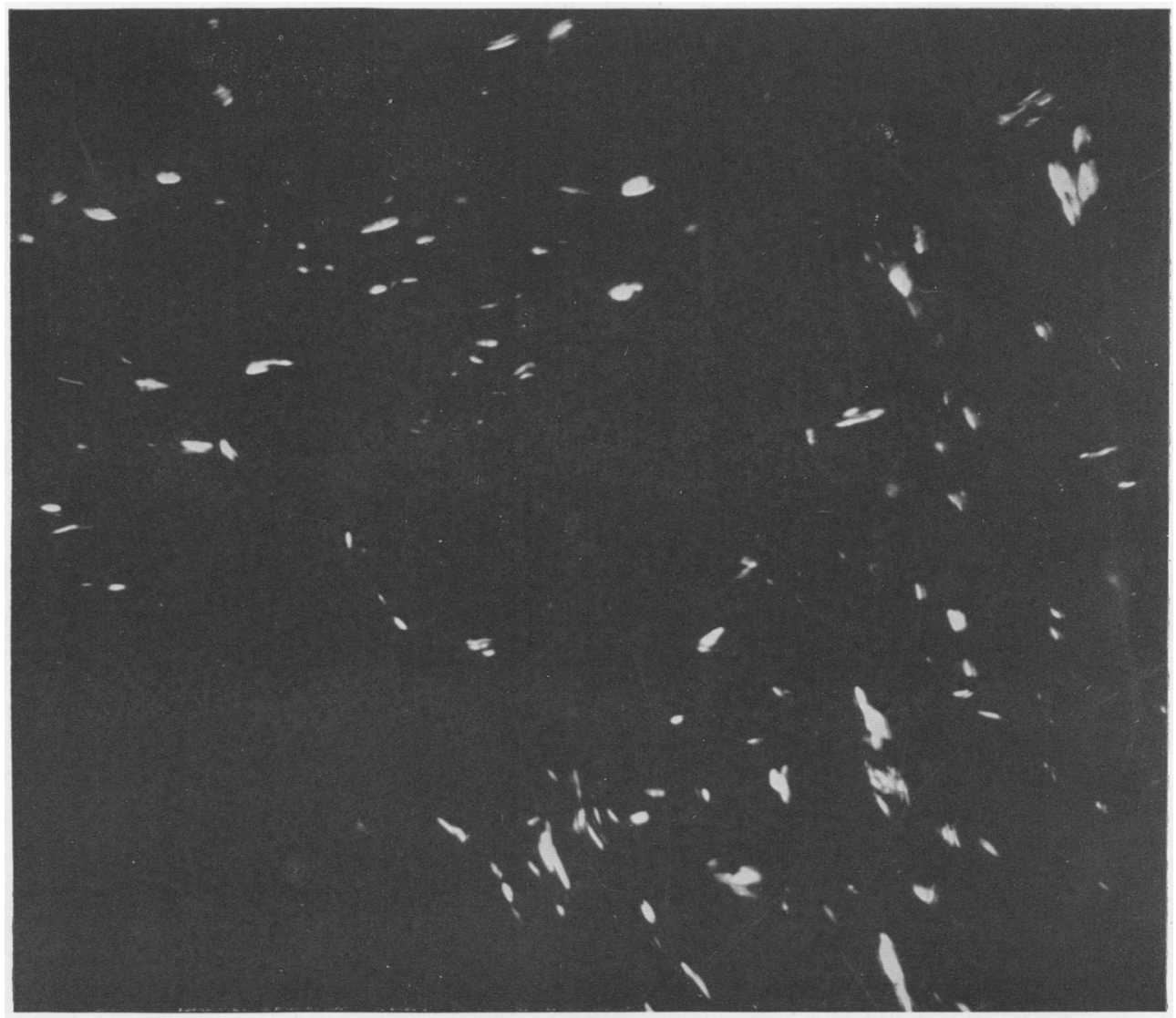

FIG. 10.-High-power photomicrograph of lung section of the same worker photographed in polarized light between crossed polaroid discs on the Vickers projection microscope. The field photographed is a portion of that shown in fig. $9 . \quad \times 535$.

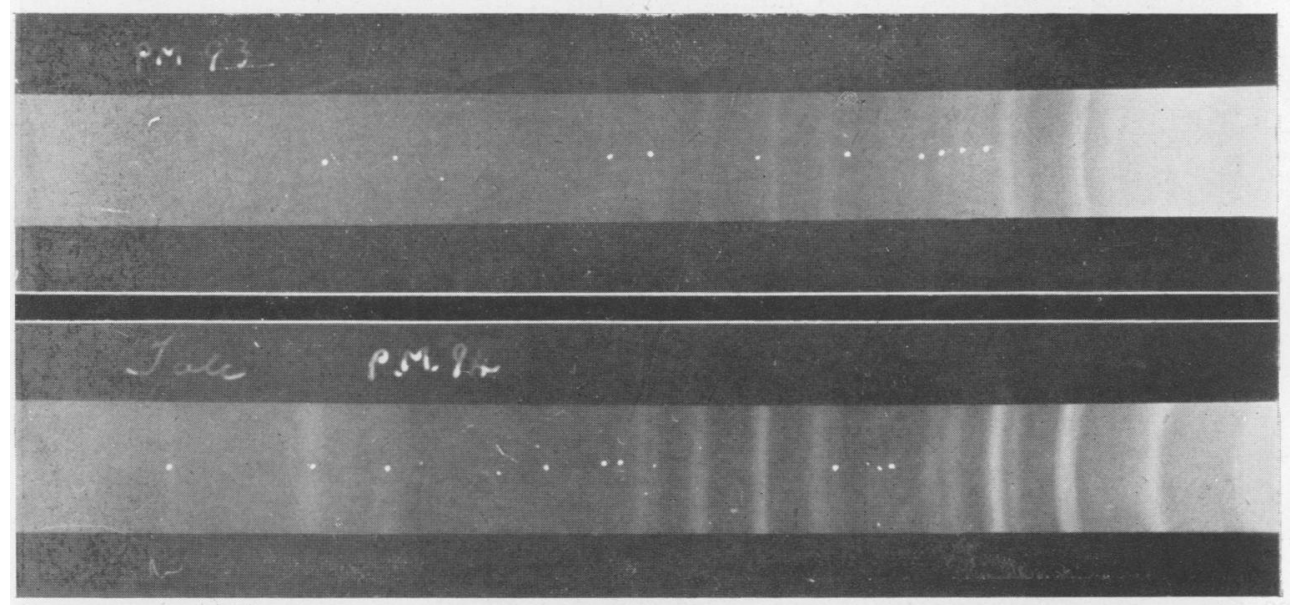

FIG. 11. $X$-ray powder photographs of mineral extracted from the lung and of talc, taken by Mr. H. J. Dothie at the Government Laboratory, using a 9-cm. camera with $\mathrm{Co} \mathrm{K} \alpha$ radiation. P.M. 93 (upper), material from the lung ; P.M. 94 (lower), talc, containing a very small amount of magnesite as impurity; supplied by Dr. T. A. Lloyd Davies. 
Journal of Surgery, describes seven cases of talc granuloma, five of which occurred in the Fallopian tubes following previous operations for appendicitis. Photomicrographs of the lesions show typical granulomatous tissue containing many doubly refractile particles.

\section{Discussion}

This is the first case of talc pneumoconiosis proved by pathological examination, to be reported in this country, and it supports the view of the American authors quoted that talc dust can produce fibrosis of the lungs. In this instance the petrographical evidence shows that as a result of prolonged exposure to dust consisting of fibres and plates of talc and equant particles of magnesitic carbonate a substantial quantity of talc fibres has been retained in the lungs. If the plates of talc ever penetrated to the lungs they must for the most part have been eliminated ; similarly no carbonate particles were found in the lungs. It is possible that the dust-eliminating mechanisms, such as the cilia and viscid secretions of the bronchial mucous membrane which protect the lungs, have prevented the ingress of plates and equant particles, while permitting the passage of minute fibres.

Asbestos nevertheless appears more actively fibrogenic than talc; otherwise one would expect many more cases of pneumoconiosis to be reported from the rubber industry in which talc is widely used. This is understandable in view of the much higher proportion of fibres in asbestos; but it is also possible that the different incidence of pneumoconiosis might be explained by variation in the dust concentrations in the asbestos and rubber industries. Complete surveys of the latter industry have not yet been made.

In the reported cases there is a remarkable histological similarity between asbestosis and talc pneumoconiosis which may be ascribed primarily to the physical form (acicular crystals) of the mineral. There are also chemical similarities between talc and the asbestos group of minerals, but as yet it is not clear how much weight should be attached to chemical factors in the causation of this disease. The presence of curious bodies, which resemble the well-known asbestosis bodies, in the lesions of talc pneumoconiosis, lends weight to the theory that the condition might be identical with asbestosis.

\section{Summary and Conclusions}

A man of 51 years of age died primarily from rheumatic endocarditis. He had worked thirtyseven years in a rubber tyre factory where he was exposed to a fair concentration of talc dust. Moderately advanced pneumoconiosis of both lungs was found at autopsy. This condition had been diagnosed during life and demonstrated radiographically.

A feature of the histology was the presence of " curious bodies" similar to asbestosis bodies associated with the pneumoconiotic lesion. Though there was much fibrosis of the lungs and abundant doubly refractile particles, an $x$-ray analysis of the lung ash suggested that there was less than 0.06 per cent. of free silica in the lung (dry weight).

A mineralogical description of the contents of the lung (mainly fibres of talc) and of talcs used at the factory to which the patient was exposed is added, and also a review of the literature relating to talc pneumoconiosis. The talc found in the lungs could have come from the Norwegian or Canadian varieties of the mineral. Both varieties are predominantly platy in form though each contains a proportion of fibres. The talc in the lungs consisted almost entirely of straight fibres, with a few curved fibres and shreds. This suggests that the respiratory passages acted as a selective filter, allowing the fibres to get into the lungs while rejecting the plates. The mineralogical observations establish clearly that fine grinding of talc gives rise to material having individual fibre form and perhaps suggests the presence of a previously unsuspected second cleavage parallel with the Zdirection.

It is likely that talc pneumoconiosis and asbestosis are similar diseases, though asbestos appears to be more actively fibrogenic than talc. The evidence suggests that talc pneumoconiosis is caused only by the fibrous varieties of talc.

Our thanks are due to Dr. E. M. Darmady who sent us the lungs, to Dr. J. S. Harper for the loan of radiographs and clinical notes, and to Dr. H. E. Harding for the chemical analyses of the lungs. We have also received much help from Dr. F. H. King. The radiographs were reproduced by the Welsh National Memorial Staff and the sections and microphotographs (figs. 1 to 7 ) by the Staff of the Department of Pathology of the Welsh National School of Medicine. Figs. 8, 9, and 10 were made by Mr. K. L. Goodall of the Factory Department. $X$-ray powder photographs were taken by Mr. H. J. Dothie of the Government Laboratory. Dr. Dunham's contribution is published with the permission of the Director of the Geological Survey and Museum.

\section{REFERENCES}

Berkelhamer, L. H. (1943). Bull. Amer. Ceramic Soc., 22, 227. Carozzi, L. (1934). "Occupation and Health," I.L.O., Geneva.

Cunningham, J. G. Quoted by Zanelli, op cit., also by Middleton, Carozzi, Pruvost, and others.

Dreessen, W. C. (1933) J. industr. Hyg., 15, 66

and Dalla Valle, J. M. (1935). Publ. Hlth. Rep., Wash., 50, 131. Duvoir, M. (1941). "La Prévention et la Réparation des Pneumoconioses." "Paris. pp. 419-21.

Emmons, R. C., and Wilcox, R. (1937). American Mineralogist, 22, 265.

Gardner, L. U. (1940). "Silicosis" Studies and Reports of I.L.O. (Series F. No. 17), Geneva. p. 40. 
Gloyne, S. R. (1938). Chapter in "Silicosis and Asbestos" (Lanza, J.), p. 225.

Jones, W. R. (1943). "Minerals in Industry." London. p. 118. McLaughlin, A. I. G., Grout, J. L. A., Barrie, H. J., and Harding, H. E. (1945). Lancet, 1 ; 337

Merewether, E. R. A. (1933-4). Ann. Rep. Chief Insp. Fact., London. 1933, p. 63 ; and 1934, p. 37.

Middleton, E. L. (1936). Lancet, 1, 61.

Nuck, K., and Szczepanski, W. (1939). “ Arbeitsmedcin." Leipzig. Quoted by Siegal, Ross Smith, and Greenburg. (q.v.)

Perry, K. M. A. (1947). Thorax, 2, 111.

Porro, F. W., Patton, J. R., and Hobbs, A. A., Jun. (1942). Amer. J. Roentgenol., 47, 507 .

(1946). North New York med. J., $3,23$.
Pruvost, P. (1946) Bull. Acad. Méd. Paris, 3rd series, 130, 202 Abst. in Arch. Malad. Prof., 1946, 7, 240.

Reichmann, V. (1944). Archiv. Gewpath. Gewhyg., 12, 317

Riddell, A. R. (1940). "Silicosis": Studies and Reports of I.L.O (Series F. No. 17). Geneva. p. 39.

Roberts, G. B. S. (1947). Brit. J. Surg., 34, 417.

Sand, R. Quoted by Devoto and Cesabianchi; National Congress for Occupational Diseases. Turin, 1911. Also by Carozzi, Duvoir, and Middleton.

Siegal, W., Ross Smith, A., and Greenburg, L. (1943). Amer. J. Roentgenol., 49, 11

Thorel, C. (1896). Beitr. path. Anat., 20, 85.

Williams, E. (1934). Lancet, $2,541$.

Williams, E. (1934). Lancet, 2, 541.

Zanelli, A. (1931). Medicina d. Lavoro, 22, 3.

\section{BOOK REVIEWS}

Demonstrations of Physical Signs in Clinical Surgery. Part IV. By Hamilton Bailey, F.R.C.S., etc. 1948. Eleventh Edition. Bristol: John Wright and Sons, Pp. 122. Illustrated in colour. Price $8 s .6 d$.

This volume completes the present edition ; it is hoped that in future the whole work will be printed in one volume, as splitting it up into parts seems unsatisfactory.

The value of this work lies to a large extent in the illustrations, and in this volume they are good. The written matter is more open to criticism but on the whole maintains the high standard of previous editions of this popular book. In the description of acute pancreatitis considerable stress is still laid on the Mydriatic test ; few observers will put as much faith in it as the author does. No mention is made of the diastatic index in the urine, but this may have been excluded as not being a physical sign. In cases of acute osteomyelitis the clinician is advised to compare the size of the regional lymphatic glands with those on the unaffected limb. As far as we know, bones do not have any lymphatic drainage ; so that if the lymphatic glands are inflamed in an early case the diagnosis is probably not acute osteomyelitis. Infection of lymphatic glands does not occur until the inflammation has spread outside the bone.

These are, however, minor criticisms of a book that can be recommended to student and doctor.

E. C. B. B.
Some Common Psychosomatic Manifestations. By J. Barrie Murray, M.A., M.D., M.R.C.P. 1949. Geoffrey Cumberlege: Oxford University Press. Pp. 101. Price $7 s .6 d$.

The book is largely devoted to a study of "effort syndrome" in a group of military psychiatric casualties. In it the author sets out to discuss the physical expressions of emotion as manifested in this disorder, which in his opinion is hysterical in type, and to evaluate the significance and relative incidence of associated symptoms. A chapter on the low back syndrome is included. Although the subject matter of this book is drawn from a military setting with its attendant artificially acute personal stresses, the numerical analysis of the physical manifestations of emotional disorder which it has been possible for the author to make in this particular group outweighs this slight disadvantage.

A vigorous plea for understanding by doctors of the psychiatric aspect of all physical disease and of the unfortunate consequences for the patient of unwisely repeated clinical examinations, over-treatment, and needless limitation of his activity, introduces a useful chapter on treatment. The book is a practical contribution of value to medical men in a field in which accurate evaluation of symptoms is at best difficult.

A. A. W. 